\title{
A Theoretical Evaluation of Enabling Humans with Social Justice, Conceptualism, and Sustainable Development
}

\author{
Yoganandham Govindharaj \\ Department of Economics, Thiruvalluvar University, Serkkadu, Katpadi Taluk, Tamil Nadu, India \\ Email: drgyoga@gmail.com
}

How to cite this paper: Govindharaj, Y. (2021). A Theoretical Evaluation of Enabling Humans with Social Justice, Conceptualism, and Sustainable Development. Journal of Human Resource and Sustainability Studies, 9, 503-523.

https://doi.org/10.4236/jhrss.2021.94032

Received: September 6, 2021

Accepted: November 9, 2021

Published: November 12, 2021

Copyright (อ 2021 by author(s) and Scientific Research Publishing Inc. This work is licensed under the Creative Commons Attribution International License (CC BY 4.0).

http://creativecommons.org/licenses/by/4.0/

(c) (i) Open Access

\begin{abstract}
The approach to human growth is to expand the wealth of life, not only the wealth of the economy in which people live. It is a people-driven approach with their choices and opportunities. People can be transforming agents if they have the power to act. However, if they remain out of touch, if essential technical technologies are not available and if they are estranged from nature, they are less inclined or are less able to do so in ways that address social forces and the plan for societal imbalances. Equal opportunity is medium, partly because the recognized disparity is mirrored in influential asymmetries. Nature management echoes the often unexpected voices of indigenous peoples and the numerous groups and cultures that view people as part of the web of world life. In human development, disparities not only symbolize unfairness and social imbalances that might destabilize mankind, affect people's happiness and self esteem but also contribute to people's environmental effect. The largest number of contribution from higher human development countries is concentrated without completely internalizing the costs. The management of nature requires the commitment and willingness of millions of individuals throughout the world, including leaders of all social sectors. As a result, the current study focuses primarily on a theoretical assessment of human potential for social justice, conceptualism, and sustainable development, all of which are desperately required and important to society.
\end{abstract}

\section{Keywords}

Human Growth, Economic Development, Theoretical Evaluation, Societal Imbalances, Equal Opportunity, Environmental Effect and Social Sectors 


\section{Introduction to the Article}

The human development approach is about expanding the richness of human life, rather than simply the richness of the economy in which human beings live. It is an approach that is focused on people and their opportunities and choices. Human development puts people at the centre of development, people are agents of change. But humans are pushing mutually dependent between social and ecological systems into the hazard region. Therefore, this paper argues enhancing fairness, developing modernism and instilling an intelligence of management of the earth.

People can be agents of transform if they have the influence to act. But they are less likely or able to do so in ways that address the drivers of social and planetary imbalances if they are left out, if relevant technologies are not available or if they are alienated from nature. On the other hand, fairness, modernism and management of environment each and, supplementary prominently, mutually can break the vicious cycle of social and environmental imbalances.

Equal opportunity is middle in part because the dissimilarity recognized is replicated in asymmetries of influence. The imbalanced sharing of nature's contributions to people and of ecological degradation's expenses is frequently entrenched in the influence of a few to benefit lacking attitude of the unenthusiastic consequences and in the disempowerment of the many that disproportionally bear the costs. The previous group represents a minority of humans that biases collective decisions. Justice can rebalance these power asymmetries so that everyone can benefit from and contribute to easing environmental forces (Anand \& Sen, 2000a). There is great probable to capture solar power and to get bigger forest areas to defend biodiversity and store carbon if people are authorizing to make those choices.

Enabling humans with social justice, conceptualism, and sustainable development is the subject of this article, which provides a comprehensive description of a theoretical evaluation. This article is divided into three parts, which is divided into ten theme sections. The first part is titled introduction to the article and it contains a discussion of the concerns, approach, and goals of the paper. The second part is labeled societal neutrality and nature's offers in different countries. Redressing country inequities, innovations to broaden opportunities and caregiver empowerment are the topics of the third part, which is followed by a conclusion.

\subsection{Description of the Issues}

To steer actions towards transformational change, it is important to empower people in three ways: by enhancing equity, by pursuing innovation and by instilling a sense of management of nature. Innovation which gave humans many of the tools to influence Earth systems can be harnessed to ease planetary pressures. Beyond advances in science from multiple disciplines that can support capturing energy from the sun and closing material cycles, innovation should be unders- 
tood here also as a social process of change, resulting from advances in science and technology that are embedded in social and economic processes. Moreover, innovation is more than science and technology; it includes the institutional innovations that ultimately drive social and economic transformations.

Management of nature echoes the often-unheard voices of indigenous peoples and the many communities and cultures over human history that sees humans as part of a web of life on the earth. Development has programmed the lessons of billions of years in the biodiversity nearby us. People depend on this biodiversity, still although are accelerating its obliteration. Instilling a sense of management of nature can empower people to rethink values, reshape social norms and steer collective decisions in ways that ease planetary pressures. Empowering people in these three ways is self-reinforcing. Inequalities bias investments in science and technology towards the powerful and alienation from nature may shift priorities away from mobilizing human creativity to ease planetary pressures. Inequalities can facilitate elite capture, with powerful and privileged groups exercising undue influence over decision makers, which can limit market competition and create barriers to entry for innovators and firms that could drive transformational change. Cultural and linguistic diversity which has evolved jointly with biodiversity implies that losses of biological diversity parallel cultural losses. Empowering people in this way can harness human agency for transformational change. The remainder of this chapter considers each of the three areas for empowerment in turn.

\subsection{The Study's Methodology}

This is a descriptive research with theoretical foundations. This study is the systematic examination of a suppositions and opinions. This form of research entails conceptualizing or describing how a theme and its surroundings operate, as well as examining or playing out the consequences of those specifications. It is based only secondary sources of information and data pertaining to the theme of the study. It is a descriptive and diagnostic design in theoretical perspectives. Secondary data is gathered from a variety of reports, both published and unpublished Materials. In addition, the libraries of the University of Madras, Madras Institute of Development Studies, Connemara public library, Directorate of Schedule Caste, Higher Education Department of India and Tamil Nadu, Directorate of Census Operations, Vellore Central Library, and Thiruvalluvar University Library were used extensively to conduct a comprehensive survey of literature in the relevant fields.

Innovation and Contribution of Research

For economic growth, new technology innovation and transmission are required. They lead to greater productivity, wealth creation, and economic well-being, as well as decent and environmentally friendly jobs. At various stages of development, innovation and technology are also critical in encouraging structural transformation of economies. They are, thus, crucial to increased 
competitiveness, through domestic policy and international cooperation, to encourage research and innovation for sustainable development and to provide broader access to technology. Countries' capacities to innovate and key to enabling for development reasons, on the other hand, vary significantly. When there is effective innovation at various levels and in all sectors, a country's capacity to benefit from technological developments through innovation is likely to be greater.

It also relies on a favourable enabling environment, which includes, among other things, physical and human capital developments, research and development investments, and policy and regulatory environments. Countries can boost their inventive capability by measuring their performance, capitalizing on their strengths, and correcting their shortcomings in innovation, as well as teach from best practices in emerging innovation leaders at all income levels. In short, the social justice and sustainability agendas are addressing the adverse implications of marginalization both in the classic political economic aspect of uneven distribution of income resources and in the environmental sense. This is important in creating an environment conducive to inclusive and long-term economic growth. Policymakers can use tools to aid in the development of their own national innovation policies (Anand \& Sen, 2000b).

\subsection{Research Article Objective}

The overall purpose of this research paper is to explore the theoretical aspects of enabling people with social justice, conceptualism and sustainable growth.

\section{Societal Neutrality and Nature's Offers in Different Countries}

\subsection{Enhancing Justice to Precede Societal Impartiality and Make Wider Preferences}

Disparities in human development not only represent unfairness and social imbalances that can destabilize humanity, touching happiness and the self-esteem of people, but they also play a responsibility in how people help with environment, impacting environmental pressures. Different disparities frequently polished relative disempowerment decide the allocation of risks transversely the population in response to changes in the biosphere. Disadvantaged groups tend to bear a larger burden. And as documented below, nature's degradation is often linked with power imbalances.

An agenda centered on fairness is significant essentially, but it can also break socio environmental traps and ultimately ease earthly pressures. The self-reinforcing cycle between social and environmental inequalities strength also emerge as socio environmental traps at lower scales, making it difficult to escape from trajectory in which persistent inequalities compound behaviors that humiliate environment and put pressure on the earth. In fact, anthropogenic risks and their consequences are closely connected to how the social order 
works. The asymmetries of power across groups can set the social conditions that result in overexploitation of resources. For instance, people and communities experiencing deprivations or a lack of power may be drawn to use inefficient production practices or to generate dangerous pollutants because of the narrow set of choices they confront.

So an agenda centered on equity is important intrinsically, but it can also break socio environmental traps and ultimately effortlessness environmental pressures. The ambition for transformational change is universally relevant, with common but differentiated responsibility due to the vast asymmetries in capacities to respond. The challenge is making the distribution of power and agency more equitable to steer action towards transformational change everywhere.

\subsection{Imbalanced Sharing of Nature's Offerings across Nations}

Higher human development countries concentrate most of nature's contributions without fully internalizing the costs generated in the process. Two tales of environmental inequalities in human development across countries are reflected in the dispersion of values along the horizontal axis of two environmental outcomes. The Environmental Health Index measures the benefits of a sound relation with the planet in terms of clean air and water and effective management of waste and residuals. The Index of Material Footprint per Capita reflects use of materials for domestic consumption. Striking inequalities emerge across countries. Low human development countries face substantial environmental challenges (they have low environmental health scores) and use much less material resources than countries at the other extreme. Higher human development countries have higher environmental health and material use scores.

The burden of planetary changes is not equally distributed across people. This is eminently destabilizing in that it rewards current production and consumption patterns. And there is more: The burden of planetary changes is not equally distributed across people. Take climate change. On average, low human development countries are likely to have 50 - 100 additional days with extreme weather by century's end, while very high human development countries might see a decrease in the number of days with extreme weather depending on the mitigation scenario.

The human impact will be huge, even after adaptation efforts are taken into consideration: The number of excess deaths in poorer countries could be comparable to those from cancer today. This is eminently destabilizing in that it rewards current production and consumption patterns. And environmental inequalities are increasing across countries. For both the Environmental Health Index and the Index of Material Footprint per Capita, the gaps are widening. This means that developed countries are improving their ability to benefit from environment through cleaner water and air faster than developing countries. At the same time, developed countries are increasing their already higher burden on the planet in material footprint, despite some recent relative decoupling be- 
tween greenhouse gas emissions and Gross Domestic Product (GDP) growth in a few very high human development countries.

These patterns are also present in integrated ecological footprint accounts, in which the net land footprint measures the costs and benefits of human activity within a territory and the carbon footprint measures the burden on the planet as a whole. While the ecological footprint indicator has some limitations, it can be informative when aggregated across large groups of countries. Very high human development countries have the largest surplus in territorial bio-capacity and the largest carbon footprint. Lower human development countries internalize a smaller surplus in land bio-capacity and externalize an even smaller carbon footprint.

Both net land footprint per capita and carbon footprint per capita increased across all development groups between 1990 and 2016. But local degradation measured using the change in net land footprint was greater in lower human development countries, while additional global pressures measured using the change in carbon footprint were greater in high human development countries, reducing horizontal inequalities to break socio environmental traps.

Conceptualizing sustainable development as "development that meets the needs of the present without compromising the ability of future generations to meet their own needs" acknowledges the interests of both present and future generations. But this conceptualization does not fully account for the complex relationship between intra-generational and intergenerational inequalities (Ballard, 2005). Neither the current generation nor future generations are homogeneous in their relationship with nature.

The differentiated use of natural resources within societies and the resulting differences in environmental degradation are fundamental to understanding how inequalities can be passed from one generation to the next and the implications for the evolution of environmental pressures. The process is complex. The nominal possession of natural resources is important, but it is far from sufficient for equitable wellbeing. There is some evidence of the so-called natural resource curse. What matters in most cases is not the availability of natural resources as such but the distribution of costs and benefits associated with them. These are influenced heavily by the interests of different groups and the relative distribution of power among them, often manifest as horizontal or intergroup inequalities. Some have deep historical roots, with origins in colonialism. The unequal distribution of power during colonial times was explicit, with colonies meant to provide natural resources for the colonial power. Power imbalances meant that most benefits were concentrated in the colonial power. Colonies retained limited rents and had their natural capital progressively depleted. The differentiated dynamics in capital accumulation, in turn, affect people's wellbeing across generations.

The differentiated use of natural resources within societies and the resulting differences in environmental degradation are fundamental to understanding 
how inequalities can be passed from one generation to the next and the implications for the evolution of environmental pressures. Racism and classism reflect similar dynamics within countries weakening long-term human development through exposure to environmental hazards, sometimes linked to extractive activities. Some groups work in precarious conditions, degrading land and depleting natural resources as part of productive processes that yield rents for the elite or large companies. In the process human rights violations intersect with unsustainable resource use.

Exploitative labour practices, including slavery and human trafficking, have been documented, for instance, across seafood supply chains around the world. Consumption often takes place in countries with strict sustainability requirements and a public sensitive to both resource overexploitation and poor working conditions, but the complexity of supply chains weakens the price and information signals that link resource use and consumption. Worse, efforts to safeguard sustainability in a location can heighten resource overexploitation elsewhere. For instance, beginning in the late 1990s, concerns about cod stocks in the Baltic Sea led to a large reduction of local cod consumption in Sweden, after strong civil society mobilization. But overall cod consumption changed little, having been met through imports. The complexity and opacity of seafood supply chains can increase even further with the growing commercial interest in marine resources. And even with progress on the most egregious human rights violations, other more subtle violations can perpetuate discrimination or deny fair access to and sharing of marine benefits.

Two long-term outcomes of these dynamics are inequality in human development and excessive resource use, potentially leading to biodiversity loss. Depletion of natural resources is likely to take place when the most powerful group has limited incentives to care about the consequences of overexploitation on others including pollution, full depletion of reserves and other environmental damages. These outcomes have little to do with preferences about the wellbeing of future generations. The dominant groups can transmit their privileges to their descendants, and the disadvantaged groups face hugely restricted choices. These outcomes have little to do with preferences about the wellbeing of future generations. The dominant groups can transmit their privileges to their descendants, and the disadvantaged groups face hugely restricted choices.

Inequalities in empowerment today are at the root of environmental problems, many threatening the wellbeing of future generations. Importance for a better tomorrow is to empower disadvantaged groups and actors today. Case studies suggest that today's intra-generational inequalities are linked to intergenerational inequality and environmental degradation through multiple channels (Barbier, 2010). Normally, these are not about income disparity but concerning a diversity of context-specific dynamics of dissimilarity that produce a negative effect on nature, including the procedural and distributional inequalities analyzed.

The local, national and global interactions underscore inequality's pervasive 
effects, including local environmental degradation, natural resource overexploitation and greenhouse gas emissions. In all the channels inequalities in empowerment today are at the root of environmental problems, many threatening the wellbeing of future generations. Therefore, an important part of the strategy for a better tomorrow is to empower disadvantaged groups and actors today. These patterns can be exacerbated by climate change. Disadvantaged groups face a disproportionate burden because of different forms of environmental imbalances, both across and within countries, which reinforce existing inequalities. One example is people living in less-favored agricultural areas and rural low elevation coastal zones. These people are already suffering the effects of climate change, which exacerbate existing poverty environment traps. One manifestation is that reduction of infant mortality is slower in these areas precisely where the problem is more intense in the first place widening gaps in human development the divergence in infant mortality contrasts sharply with the convergence observed on average across developing countries, with greater reductions in poorer countries underscoring how environmental factors affect social imbalances.

Thus, inequalities, particularly horizontal inequalities, can drive both environmental degradation and intergenerational inequality. Enhancing equity can empower people to advance human development and ease planetary pressures. More cohesive societies have social mechanisms that can reduce gaps in empowerment encoded in legislation and policies, ranging from fiscal measures both taxation and social protection to regulation and competition policies which preclude the excessive concentration of economic power in monopolies. In less cohesive societies group-based inequalities, amplified by environmental factors, can generate social costs that have inspired social mobilization, such as the environmental justice movement (Barbier, 2016).

\section{Redressing Country Inequities, Innovations to Broaden Opportunities and Caregiver Empowerment}

\subsection{Redressing within Country Inequalities to Ease Pressures on the Planet}

But it is not only horizontal inequalities that matter. Addressing inequalities across people can also enable societies to advance human development while limiting planetary pressures. Consider the current frontiers of achievement in life expectancy at birth and mean years of schooling for different incomes. For any income level there is wide variation in health and education outcomes, pointing to the potential for enhancing both without increasing income and associated planetary pressures. In other words there is much potential at every income level for advancing human development by closing gaps in achievements in health and education, advancing equity in either dimension.

Progress in equity might also contribute to resetting priorities. Within-country inequality can be a factor behind the social need to increase material consumption and the importance of economic growth in generating opportuni- 
ties for those less well off. With high inequality there are expenditure cascades and moving targets: People make progress in material conditions, but it does not necessarily translate into greater capabilities or sizeable increases in happiness. In more unequal societies there is a greater search for status through consumption, sometimes leading people with low income to reduce caloric intake in favour of aspirational purchases. Tragically, low-consuming and socially equitable communities, such as many indigenous peoples, have been increasingly marginalized. In sum, greater equity can be a powerful social stabilizing force and ease environmental pressures (Burton \& Kates, 1986).

It is not the only factor, and enhancing equity alone may not lead to these outcomes. That is why, along with equity, it is crucial to empower people through innovation and a sense of management of nature. For instance, the equity lens is fundamental for transformations in the energy sector to achieve decarbonization. Indeed, some key instruments for decarbonization such as carbon prices and reduced fossil fuel subsidies have complex distributional impacts. This might feed a narrative of conflict between equity today and the wellbeing of future generations, complicating the political implementation of these measures. The tension can be relaxed if policymakers embed equity considerations in policy design. Compensatory packages and affordable alternatives are to carbon-intensive goods and services. Much of this can also be facilitated by innovation, be it renewable energy at competitive prices or innovations in allocating fiscal resources. Management of nature should also have an equity component. As chapter 6 discusses, a new generation of bottom-up policies simultaneously targets the responsible use and protection of the environment and advancement of human development (Cialdini \& Goldstein, 2004). In many cases, their success depends on empowering indigenous peoples and local communities.

\subsection{Pursuing Innovation to Widen Opportunities}

The generation and diffusion of new ideas and technologies have improved people's wellbeing but have also given humanity the instruments to capture energy, use materials and put pressure on the biosphere that have resulted in today's unprecedented planetary imbalances. Some were unintended consequences of technical change, as with synthetic fertilizers that vastly increased crop productivity but are now disrupting the nitrogen cycle. On a planet with bounded resources, ideas and the ability to use resources in ever more efficient ways have enabled human flourishing. More important than any single idea or technology is the pursuit of innovation, broadly understood, in what Stiglitz and Greenwald call learning societies. Shifting towards renewable energy and closing material cycles would be important manifestations of the transformational change to ease planetary pressures. For energy the goal should be decarbonization, ideally towards capturing energy directly from the sun, a limitless source of energy on human timescales. For materials the goal should be reducing waste and converging towards closed material cycles. These two goals require substantial 
technological innovation, along with broader economic and social innovations that ultimately determine the impact of new technologies on people and planet. Shifting towards renewable energy and closing material cycles would be important manifestations of the transformational change to ease planetary pressures. These two goals require substantial technological innovation, along with broader economic and social innovations (Cialdini \& Goldstein, 2004).

The pace of technological change, for issues ranging from artificial intelligence to gene editing, is such that new institutions that cannot necessarily be predicted in advance may be required. This is in part because science has to confront normative and value-laden issues, and the challenges of the Anthropogenic bring new dimensions. The process of innovation, social and technological, is likely to continue to evolve and accelerate given that our "collective brain" expands and becomes more interconnected, facilitated by digital technologies, for instance, a recently identified material exhibiting.

Superconductivity at room temperature but at high pressure could dramatically reduce losses in energy transmission and the need for energy storage. In fact, digital technologies may directly ease planetary pressures and advance human development, even though there are also risks, as discussed below. From mobile payments to crowd funding, digital technology is already a critical enabler in development. During the Covid-19 pandemic digital technology has proved indispensable for work, education, health care and staying connected. An expanded digital sphere has also eased planetary pressures, showing a way forward if temporary changes in behaviour can become more ingrained. The United Nations Secretary-General's high-level Task Force on Digital Finance made several recommendations to leverage digital finance for attaining the Sustainable Development Goals. It concluded that digitalization will give people greater control over how global finance their own money is used (Chhibber, 2020). The democratization of finance, enabled by digitalization, could empower people by ensuring that their values are translated into how global finance is channeled, as when taxpayers hold governments to account or investors hold financial institutions to account.

Technological breakthroughs without changes in regulations and behaviors are not enough to ease planetary pressures. Data and artificial intelligence applications also have a big impact from their own energy use. The sharing economy has connected excess food that would likely go to waste with food-insecure households. In high-income countries most food waste is at the retail and consumer stages. OLIO is an app for food sharing that aims at reducing food waste and is rendered as OLIO. It does this by linking surplus food people to others who need or want to eat it. It might be raw or cooked, sealed or open. The food has to be edible. It is a popular food-sharing platform in the United Kingdom, has successfully distributed percent of the 170,000 listings for food items on its website, diverting a substantial amount of food from waste. Artificial intelligence based technologies can also increase recycling rates. Digital technologies can 
monitor resource use and illegal resource extraction.

Technological breakthroughs without changes in regulations and behaviours are not enough to ease planetary pressures. Data and artificial intelligence applications also have a big impact from their own energy use. While there is no standard method for calculating internet-related energy consumption, estimates suggest that approximately percent of global electricity in was consumed by information and communication technology. The carbon footprint of training a single artificial intelligence system can be as much as tonnes of carbon dioxide equivalent five time the lifetime emissions of the average car. Each year global online video streaming produces as much emissions as Spain (Cortese, 2003). The digital economy also makes an impact through its material footprint large and growing including in the form of electronic waste.

Sometimes temporary incentives are enough to redirect technical choices towards clean technologies. When two technologies, clean and dirty, are relatively substitutable, an unregulated economy would head towards environmental damage because the initial productivity advantage of dirty technologies would lead profit-maximizing firms to adopt them. However, with environmental regulation, taxes and subsidies, technical change can be redirected. Once clean technologies are advanced enough, firms will adopt them and invest in research and development to cultivate them further.

Beyond innovation, diffusing new technology across an economy and across international borders is crucial. Many factors are at play. One challenge is to make the economic, social and political systems that embed science and technological change cognizant of planetary pressures (Daly, 1992). The next two sections zoom in on technological innovations that can support the energy transition and the closing of material cycles.

Sources require new technologies and the diffusion and adaptation of existing technologies. Switching from mainstream established energy production can be challenging. Governments and investors with a long-term horizon can invest in new promising technologies, bringing them close to the point where they can compete in price with incumbent technologies. This is an example of a sensitive intervention point take investments in solar photovoltaics. Deployment has clearly resulted in falling costs, and public policies could accelerate progress by neutralizing resistance to change based on economic costs. The real cost of photovoltaic modules has dropped by more than a factor of since 1956 and by 89 percent since 2010. If their deployment continues to increase at the current rate, its price is likely to fall considerably. In addition, the right sequence of policies can create political conditions for more ambitious climate policies in subsequent rounds of debate and policymaking, as in California and the European Union, where policymakers first supported low-carbon technologies and then carbon trading schemes. And across the world, national policymaking has taken up the charge for promoting renewable energy.

In 2008 India launched the National Action Plan on Climate Change, a sensi- 
tive intervention point because it was a formal recognition of the threat of climate change and the need to act at home, even as international negotiations were ongoing. Under the Paris Agreement, India pledged to reduce the emission intensity of its GDP from the 2005 level by 33 - 35 percent by 2030 and to obtain 40 percent of electric power capacity from non-fossil fuel sources by 2030 .

In 2019 India ranked fifth for installed solar capacity. With solar, wind and other intermittent sources of energy, complementary technologies such as storage systems are important and here too prices are falling. Integrating renewable in the mix of energy sources requires smart electric grid transmission systems that can integrate renewable and conventional sources of supply (Dasgupta, 2001). Smart grids are electricity networks that can intelligently integrate behaviour and actions of all users connected to it generators, consumers and those that do both to efficiently deliver sustainable, economic and secure electricity supplies. This involves a host of technologies, including smart meters, that measure output and consumption in real time, and algorithms to share and manage the data to unlock efficiency gains.

Electricity markets may also need to be redesigned. Nowadays, the price of electricity typically does not vary with supply and demand over short timeframes, but variable pricing which adjusts frequently, even within the same day, in response to changes in demand and intermittent supply may be more appropriate for systems that have a high share of energy from renewable.

Despite these advances and future potential, challenges persist. The political economy of displacing established sources, such as coal-based power generation, is complex. Economic growth will continue to put upward pressure on total energy demand and emissions. Energy efficiency is crucial in mitigating the rise of greenhouse gas emissions from the expanding pace of worldwide energy demand. But in 2018 primary energy intensity improved by just 1.2 percent, the slowest rate since 2010. And as the technology frontier expands, access to the latest technologies by developing countries becomes ever more relevant. Developing countries face a dual challenge like Many of them are still working towards universal access to electric power while moving towards renewable energy. There are many impediments to accessing solar photovoltaics, batteries and smart grids. Financing and intellectual property regimes will be key to deploy these technologies at scale in developing countries. With solar, wind and other intermittent sources of energy, complementary technologies such as storage systems are important and here too prices are falling. Direct air capture requires stripping carbon dioxide out of the atmosphere with renewably powered open-air chemical engineering.

This idea is being implemented in experimental installations in Canada and Switzerland. One issue is that it requires a substantial amount of energy and water. As they currently stand, these technologies face scepticism and concerns that their claims on land use could compete with food production, drive biodiversity loss and deplete water. Ultimately, the potential of negative emissions technolo- 
gies will depend on adopting a portfolio of approaches and of further scientific and technical advances, which can be encouraged with structured incentives for innovation. Technological solutions have also been proposed for directly capturing carbon dioxide from the atmosphere with negative emissions technologies, such as carbon capture and storage (Jiang, 2008). Some involve storing atmospheric carbon dioxide in geological formations. Despite considerable research, carbon capture and storage have not been widely deployed due to a range of technical, economic and commercial challenges. Another negative emissions technology, bio-energy with carbon capture and storage, requires growing plant biomass to sequester carbon dioxide from the atmosphere, harvesting the biomass and burning it for energy, while capturing the carbon dioxide emissions from the power stations and storing the waste underground.

According to the European Commission, the transition to a more circular economy, where the value of products, minerals and resources is maintained in the economy for as long as possible, and the generation of waste minimized, is an essential contribution to the EU's efforts to develop a sustainable, low carbon, resource efficient and competitive economy. But strong incentives for a circular economy cannot simply displace linear economy activities to places lacking those incentives. For instance, firms headquartered in countries with strict environmental policies might perform their polluting activities abroad in countries with weaker policies, with evidence suggesting that when this happens, it is driven primarily by an incentive to avoid tight environmental policies in home countries rather than by purposefully pursuit of places with lenient environmental policies.

Strong incentives for a circular economy cannot simply displace linear economy activities to places lacking those incentives. Consider food systems. Nitrogen, phosphorus and potassium are essential for food production and life about half the world's food production depends on mineral micronutrient fertilizers. For the most part these fertilizers have been used with little consideration of their disruptive effects on biogeochemical cycles and even the local environment. Take nitrogen. The Earth's natural nitrogen cycle, with robust feedback and controls, is steered by a suite of microbial processes.

It was a technological breakthrough, the Haber-Bosch industrial process developed in the early 20th century, that enabled the production of ammonia, a chemically reactive, very usable form of nitrogen, to be synthesized using atmospheric nitrogen, heralding the age of large-scale production and application of agricultural fertilizers. Since the introduction of the process, reactive nitrogen in the Earth system has increased 120 percent over the Holocene baseline. This reactive nitrogen largely ends up in nitrogen-limited ecosystems, leading to unintentional fertilization, loss of terrestrial biodiversity and lower quality surface and ground waters in coastal ecosystems. Added to this are nitrogen oxides from fossil fuel combustion. Globally, million new pediatric asthma cases a year are attributable to nitrogen dioxide pollution, 64 percent of them in urban centres. 
From more effective planting to minimizing postharvest losses in storage, there are several opportunities for efficiency increases throughout the food chain. However, there is a lot of room for improvement because there is so much leakage and inefficiency at every stage. Humans consumed only 17 teragrams of nitrogen in crop, dairy, and meat products in 2005, despite the fact that nearly 100 teragrams of nitrogen were sprayed in global agriculture. The efficiency of nitrogen utilization in major crops is less than 40 percent. The majority of fertilizer applied is washed away or lost to the atmosphere. And a large portion of agricultural output is simply thrown away. Food waste is responsible for 8 percent of worldwide anthropogenic greenhouse gas emissions, 20 Percent of freshwater use, and 30 percent of global agricultural land use. From more effective planting to minimizing postharvest losses in storage, there are opportunities for efficiency increases throughout the food chain.

This includes increasing the efficiency of food consumption patterns and improving human and animal waste treatment. Some tried-and-true methods, such as regular crop rotation, can be beneficial. In maize production, for example, legume planting provides nitrogen that would otherwise be supplied by synthetic fertilizers. Improving agricultural efficiency in general necessitates a wide range of technologies, including new food production processes including precision agriculture. Technologies could be used to gain a better understanding of the existing situation perhaps through satellite-based observation and to help develop efforts to reduce planetary stresses. Breeding for ancient and new crops with a specific goal in mind could provide viable options for meeting human requirements. Changing one's diet could improve the efficiency with which agricultural inputs are used.

The Human Development Report has a long history of looking beyond people's basic needs to see how enhanced freedoms for all people match with environmental management. The 2008 Human Development Report looked at how to manage the planet as a major pillar of a long-term, inclusive climate change response. We are resuming our efforts to empower people through environmental management, which is defined as the responsible use and protection of the natural environment through conservation and sustainable practices in order to improve ecosystem resilience and human well-being.

For current and future generations, this management is accompanied with goals of social justice, expanded liberties, and control over one's own life. Philosophical approaches those priorities both thriving people and a thriving earth can help to assist management. This necessitates an awareness of how the relationship manifests in intellectual traditions, old knowledge often codified in religions and taboos, and social behaviours, as well as how it has manifested in the past.

Buddhism, Christianity, Hinduism, Islam, and Judaism, for example, have developed intricate notions of intergenerational justice and shared responsibility for a shared environment over time. The Quadratic notion of "tawheed," or 
oneness, encapsulates the concept of creation's interconnectedness across generations. There is also an obligation to protect the Earth and its natural resources for future generations, with humans serving as guardians of the natural world. The encyclopedia Laudato Si, published in 2015, offers a Christian view that includes our connection to nature and the idea of the world as our shared home, which we have a moral obligation to conserve.

Philosophical traditions all throughout the world recognize our humanity as part of a greater network of links that includes all living things. These viewpoints can assist us in rethinking and reshaping our locations in the world. Many indigenous peoples believe that flourishing societies are built on egalitarian and long-term partnerships. Well-being and development begin where our lives intersect with those of others and with the natural world.

These crossroads result in obligations for remembering and learning from the past, as well as for establishing equitable and sustainable conditions in the present and future (Nagoya Declaration on Higher Education for Sustainable Development, 2014). The idea that negotiating our complicated duties to people and other living things is vital to understanding ourselves and leading lives we have reason to value is at the heart of global rights of nature movements.

These kinds of understandings aren't exclusive to indigenous peoples. Recognizing human-nature linkages may be seen in communities and sociology environmental movements all over the world, from global youth climate justice movements to local environmental preservation and low-carbon efforts. These new viewpoints allow us to re-weave our close, caring bonds with nonhuman natures in all of their many personalities and skills (Otter, 2007). They do so by emphasizing the importance and urgency of environmental issues, the significance of diverse knowledge, and the necessity for both local and global solutions.

These movements bring into light how human flourishing concerns people who are related to each other, to nonhuman nature, and ultimately to our planet through changing the way we think about our places in the world. The enormity and severity of today's perilous planetary change necessitate a broad response to reclaim some of that knowledge.

The extensive literature on environmental management offers concepts and ideas that are a good place to start. Motivations, capacities, and agents, according to Nathan J. Bennett and colleagues, are three key factors that are influenced by the socioecological setting and merge to produce both environmental and social outcomes (Sakalasooriya, 2021). Human development and agency can be used to investigate these three elements.

Intrinsic and extrinsic motivation is two different but connected methods to understand why we as humans should care for the earth. Intrinsic motivations are the factors that contribute to an individual's and society's well-being. They are intertwined with our core values and beliefs about what it means to have a happy life. Extrinsic motives are tied to external rewards or sanctions, whether social, legal, or financial, as well as a cost-benefit analysis of environmental ste- 
wardship. Individuals, communities, and societies all have a combination of intrinsic and extrinsic drives, which are analytical categories (Sterling, 2003). On the other hand, enables for the identification of bottlenecks and chances for general motivation strengthening in various contexts. Identifying the external and internal drivers and reasons for environmental protection is also related to the concept of human development and agency, in which a given development outcome, such as education, is valued not only for its external rewards jobs and salaries but also as something in and of itself, as a positive freedom (Sterling, 2004).

There are several examples of both sorts of environmental motivation. Religious ideas could be used as examples of intrinsic drive. Others are concerned with how indigenous peoples and other local cultures have dealt with natural entities. Indigenous socio-environmental movements have evolved into political signifiers capable of expressing our shared humanity, based on indigenous ideologies. These ideologies are based on a deep regard for one another as well as the natural world.

These movements place human nature relationships at the centre. Such a relational approach draws out the interdependence of all things for wellbeing and the reciprocal relationships among people and between people and the planet. Other fundamental ideas define and focus collective duties to safeguard and improve socio-environmental interactions.

In Aotearoa, such multidimensional and community-engaged understandings of health continue to inform health service delivery and policy. Other projects aim to strengthen community and cultural capacity in order to accelerate the transition to low-carbon futures. A big part of their job entails describing the different ways in which land and water development efforts can improve and protect local communities and relationships between people and the environment. Communities' needs and ambitions, driven by intergenerational ideas and practices, are aimed at securing routes to a more sustainable and just future.

Reciprocity, relationality, and a great respect of the diversity and a stress on the complementarities among human beings and between human beings and the natural environment are central to the good life. In India indigenous ideas value collective responsibility and obligation to care for land, family, and community. Western India, relate to the interconnection of strong states and strong language, strong spirit or good feeling. These connections are exemplified by intergenerational transfer of knowledge and practice, as well as reciprocal sharing of gifts from lands and seas. However, these linkages are strongly reliant on the ability to live in ways that they value and to carry out these responsibilities.

Similarly, the good life is based on relationships and the necessity for collaboration and justice among all beings. The way all entities of Creation have duties and responsibilities to each other underpins the continuity of creation and the relationships important to responsibilities to creation and re-creation. This philosophy can be found in social and environmental movements, as well as gov- 
ernment and law.

Reciprocity, relationality and a great respect of the diversity and an emphasis on the complementarities among human beings and between human beings and the natural environment are central to the good life. Similarly, reciprocity is one of the most essential tenets for the people, as the saying what is received must be returned in equal measure illustrates. These and other notions enabled and assured that agricultural systems were based on sustainable production practices and food security. External incentives, in which environmental stewardship and respect result in additional advantages, are also widely demonstrated. Payments for certain management measures, payments for ecosystem services, and market premiums for more environmentally sustainable products.

Aside from incentives, the environmental management framework takes into account agents' ability to carry out management actions. People's and communities' ability to carry out specific activities that benefit the planet will be determined by communal and individual assets such as infrastructure, technology, financing, income and wealth, rights, knowledge, skills, leadership, and social relations, as well as decision-making structures within and across communities and groups (Tilbury, 2013). Governance, defined as the process by which state and non-state entities interact to reach and maintain agreements, is crucial.

The allocation of power, as discussed previously in this chapter, shapes and is affected by these exchanges, and the agreements established are sometimes referred to as institutions. And, wherever power disparities exist, the poorest members of society end up losing more by empowering people for equity. The 2019 Human Development Report looked at the elite capture of institutions, where powerful interest groups limit government policy's ability to redress inequities. The distribution of power in society is then reflected in policy results, as previously stated in this strengthening equity is critical. Indigenous peoples can teach us about governance once again. Making judgments that are in tune with the planet is a part of indigenous cultures all over the world, and it is the consequence of finely tuned knowledge gathered over long periods of time, not by chance. To survive and ensure that their natural world would provide resources in the future, indigenous societies developed a thorough awareness of it.

Many behaviours and traditions that encourage a general concept of sustenance rather than waste reflect this requirement to live sustainably. Abuse of the earth, its animals, and plants was frowned upon in the past and is still frowned upon today by elders. Many other indigenous societies came to a similar understanding of disconnectedness and used it to build meticulous land and water management methods, as well as more general development tactics. And they restrict what you can hunt, when you can hunt it, who can hunt it a whole area of forest can be closed off from hunting or gathering activities in order to let it rest. These behaviours show a dedication to what calls Collective Continuance, or a community's potential to be flexible in ways that allow its members' livelihoods to thrive into the future. Not only does this include the ability to respond 
to and adjust to changes as they occur, but it also necessitates the ability to challenge long-standing inequities such as colonial difficulties, as well as the ability to forge strong and cohesive relationships at all levels of involvement.

The rights of the peoples concerned to the natural resources pertaining to their lands shall be specially safeguarded. These rights include the right of these peoples to participate in the use, management and conservation of these resources. Although considerable work remains to be done to ensure indigenous and tribal peoples' rights, particularly in nations with deep seated inequality. It seeks to regulate and operationalize the participation of indigenous peoples in environmental decision-making and political processes on questions where their interests are directly affected. While free, prior, informed consent is a welcome development in participatory processes, it still raises concerns and challenges. An adequate bottom-up approach would recognize indigenous peoples' right to self-determination while allowing the state to mediate and solve conflicts, strengthen local representative and democratic institutions, recognize existing national legislation and solve any contradiction emerging from the process. Moreover, free, prior, informed consent is not immune to elite capture, and with large power imbalances it can be detrimental.

\subsection{Empowerment of Caretakers}

Nature management demands that billions of people worldwide, including leaders in every field of society, be committed to, and willing to build communities and societies. The connection with Nature, the Planet and every living thing can create a new sense of agency and responsibility. It will certainly take a lot of training by doing to address the challenge of expanding human freedoms balanced with the planet. Usually innovation takes place from the bottom up, driven by a small-scale human agency and with the scope to expand if successful. Nature management demands that billions of people worldwide, including leaders in every field of society, be committed to, and willing to build communities and societies.

Amartya Sen defines an agent as a person whose accomplishments can be judged by his/hers own values and goals and who acts and changes, regardless of whether we evaluate them in relation to certain external criteria. Sen has further argued the need for new ways of thinking, including the recognition of a central tenet, to repension the relationship between people and the planet. In his words, we must not only consider maintaining the satisfaction of our needs, but also, more generally, sustaining and extending our freedoms. By recognizing people as reflective agents rather than passive patients, ecosystems can be preserved and species preserved. Sen's argumentation is based on people's ability to act on their own will, reason and value.

It places people at the centre, their freedoms and their ability for change. Stewards may be individuals or groups organized to varying degrees. Their actions may be taking place at a varied level, at the community, ecosystems, domestic or 
even global level. The examples described here suggest numerous management opportunities that reflect the complex interaction between people and the planet. Several levers can be used to increase management, including the reduction of species harvest, establishment of marine protected areas, management of wetlands and the establishment of and maintenance of urban green spaces and gardens, as well. Broader start-ups might extend to transboundary and regional scales (World Commission on Environment and Development, 1987). Successful management does not only require motivated players with the ability to push the agenda, it also requires a clear monitoring system in which measurement can assess the results and the foundations for innovation and learning are assessed.

\section{Limitations}

Because the study's scope is so broad, any conclusions or inferences taken from it may not be universally applicable or accepted. Outside of its field, this article is unable to uncover information. Furthermore, it just investigates society for facts and does not offer suggestions. It is inevitable that the research will have some limits, which is to be expected. Nonetheless, it is crucial to strive to reduce the range of scope of constraints as much as possible throughout the article preparation process. In addition, it must honestly address the research limitations. This paper may have several restrictions, but only those that are closely relevant to the research topics should be discussed.

\section{Conclusion}

Firstly, that social justice forms part of the concept of sustainable development outlined in the common future by the World Committee on the Environment and Development. The definition of this reconciliation is sustainable development. The SDGs are a globally accepted instrument for assessing progress in development of Sustainable Development Goals. In other words, the sustainable development objectives are a destination for development. Social justice is designed to ensure that persons and groups receive fair treatment. Environmental justice is primarily concerned with the positive and negative impacts on communities and individuals which various environmental factors can have. Both environmental benefits and disadvantages can arise.

The 1987 Bruntland Commission report describes the concept of sustainable development as development that satisfies current needs without jeopardizing future generations' ability to meet their needs. Thus, the opportunity to play a leading role in contributing to a sustainable future is a particular aspect of global social justice. It is regretted that while a number of senior higher education managers have demonstrated a commitment of their university to sustainable development and social justice, they have, in principle, failed to address the strategic questions which a serious commitment to this agenda poses to the institutions themselves as signatories to numerous international declarations. Although admitting the popularity of this paradigm in higher education, it is also preva- 
lent in the sphere of international organizations, where the approach and techniques of assembling operations are radically altered in response to sustainable development.

As mentioned, this requires bold leadership to challenge and transform the state of affairs. The qualities of global leadership are much in common with an effective leader's general qualities, but with a distinct focus on transformation, emotional intelligence and learning. It is suggested that greater attention should be paid to the related aspects of leadership, and that greater diversity could improve the capacity for transformation approaches at Board and Executives level. Humans urge world leaders to support the transformative role of universities and to collaborate and to promote transformative learning and research by fostering partnerships with multi-stakeholder groups, sharing examples of sustainable development practices, supporting strong and broad leadership, and public awareness of the values of sustainable development. Researchers suggest that transformation begins at the university management level and seeks a new way of building higher schools in order to respond more to our agenda and to contribute to sustainable communities and the requirements of future generations.

\section{Conflicts of Interest}

The author declares no conflicts of interest regarding the publication of this paper.

\section{References}

Anand, S., \& Sen, A (2000a). Human Development and Economic Sustainability. World Development, 28, 2029-2049. https://doi.org/10.1016/S0305-750X(00)00071-1

Anand, S., \& Sen, A (2000b). The Income Component of the Human Development Index. Journal of Human Development, 1, 83-106. https://doi.org/10.1080/14649880050008782

Ballard, D. (2005). Using Learning Processes to Promote Change for Sustainable Development. Action Research, 3, 135-156. https://doi.org/10.1177/1476750305052138

Barbier, E. B. (2010). Poverty, Development, and Environment. Environment and Development Economics, 15, 635-660. https://doi.org/10.1017/S1355770X1000032X

Barbier, E. B. (2016). Sustainability and Development. Annual Review of Resource Economics, 8, 261-280. https://doi.org/10.1146/annurev-resource-100815-095227

Burton, I., \& Kates, R. W. (1986). The Great Climacteric, 1798-2048: The Transition to a Just and Sustainable Human Environment. In R. W. Kates, \& I. Burton (Eds.), Geography, Resources, and Environment (pp. 339-360). University of Chicago Press.

Chhibber, A. (2020). Variations on the HDI for the Anthropogenic: Broadening the Vista. Background Paper for Human Development Report 2020, United Nations Development Programme, Human Development Report Office.

Cialdini, R. B., \& Goldstein, N. J. (2004). Social Influence: Compliance and Conformity. Annual Review of Psychology, 55, 591-621. https://doi.org/10.1146/annurev.psych.55.090902.142015

Cortese, A. D. (2003). The Critical Role of Higher Education in Creating a Sustainable Future. Planning for Higher Education, 31, 15-22. 


\section{https://doi.org/10.1016/0921-8009(92)90024-M}

Daly, H. E. (1992). Allocation, Distribution, and Scale: Towards an Economics That Is Efficient, Just, and Sustainable. Ecological Economics, 6, 185-193. https://doi.org/10.1016/0921-8009(92)90024-M

Dasgupta, P. (2001). Human Well-Being and the Natural Environment. Oxford University Press. https://doi.org/10.1093/0199247889.001.0001

Jiang, X. (2008). Towards an Internationalization of Higher Education from a Critical perspective. Journal of Further and Higher Education, 32, 347-358. https://doi.org/10.1080/03098770802395561

Nagoya Declaration on Higher Education for Sustainable Development (2014, November). http://www.c-linkage.com/for/hesd/declaration.html

Otter, D. (2007). Globalisation and Sustainability: Global Perspectives and Education for Sustainable Development in Higher Education. In E. Jones, \& S. Brown (Eds.), Internationalising Higher Education (pp. 42-54). Routledge.

Sakalasooriya, N. (2021). Conceptual Analysis of Sustainability Development. Open Journal of Social Sciences, 9, 396-414. https://doi.org/10.4236/jss.2021.93026

Sterling, S. (2003). Whole Systems Thinking as a Basis for Paradigm Change in Education: Explorations in the Context of Sustainability. Doctoral Dissertation, Centre for Research in Education and the Environment, University of Bath.

Sterling, S. (2004). Higher Education, Sustainability, and the Role of Systemic Learning. In P. B. Corcoran, \& A. E. J. Wals (Eds.), Higher Education and the Challenge of Sustainability (pp. 49-70). Springer. https://doi.org/10.1007/0-306-48515-X 5

Tilbury, D. (2013). Another World Is Desirable: A Global Rebooting of Higher Education for Sustainable Development. In S. Sterling, L. Maxey, \& H. Luna (Eds.), The Sustainable University: Progress and Prospects (pp. 71-86). Earthscan/Routledge.

World Commission on Environment and Development (1987). Our Common Future. Oxford University Press. 